\title{
TOWARD AN INTEGRATED SEISMIC RISK ASSESSMENT FOR NUCLEAR SAFETY IMPROVING CURRENT FRENCH METHODOLOGIES THROUGH THE SINAPS@, RESEARCH PROJECT
}

Catherine Berge-Thierry ${ }^{1}$, Pierre-Yves Bard ${ }^{2}$, Thomas Chartier ${ }^{3}$, Régis Cottereau ${ }^{4}$, Etienne Bertrand $^{5}$, Fernando Lopez-Caballero ${ }^{4}$, Didier Clouteau ${ }^{4}$, Stéphane Grange ${ }^{6}$, Silvano Erlicher ${ }^{7}$, Fabrice Hollender ${ }^{8}$, Panagiotis Kotronis ${ }^{9}$, Maria Lancieri ${ }^{3}$, Aurore Laurendeau ${ }^{8}$, Alain Le Maoult ${ }^{8}$, Nadim Moussallam ${ }^{10}$, Marc Nicolas ${ }^{8}$, Frédéric Ragueneau ${ }^{11}$, Jean-François Semblat ${ }^{12}$ and François Voldoire $^{13}$

${ }^{1}$ Atomic Energy Commission Senior Researcher \& SINAPS@ Coordinator, CEA/DEN/DANS/DM2S

France

${ }^{2}$ Researcher \& Engineer, ISTERRE, France

${ }^{3}$ Researcher, Institut de Radioprotection et de Sûreté Nucléaire, France

${ }^{4}$ Researcher, Ecole Centrale Paris, France

${ }^{5}$ Researcher, CEREMA, France

${ }^{6}$ Researcher, INP-Grenoble \& Université Joseph Fourier, France

${ }^{7}$ Engineer (Technical and Scientific coordinator) EGIS, France

${ }^{8}$ Atomic Commission Researcher, France

${ }^{9}$ Professor, Ecole Centrale Nantes, France

${ }^{10}$ Engineer, AREVA, France

${ }^{11}$ Professor, Ecole Normale Supérieure de Cachan, France

${ }^{12}$ Professor, IFSTTAR, France

${ }^{13}$ Senior Researcher -Engineer, EDF (R\&D) and Institute of Mechanical Sciences and Industrial Applications, EDF-CNRS-CEA-ENSTA UMR 9219, France

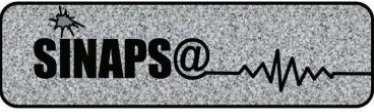

\begin{abstract}
The Tohoku earthquake and associated tsunami in March 2011 caused a severe nuclear accident at the Fukushima Daiichi Nuclear Power Plant, where level 7 (International Atomic Energy Agency (IAEA) INES scale) meltdown at 3 reactors occurred. The underestimation of the seismic and tsunami hazards has been recognized and the seismic margins assessment of the NPPs remains a priority for the whole nuclear community. In this framework an ambitious 5 years research project called SINAPS@ (Earthquake and Nuclear Installations: Ensuring and Sustaining Safety) is currently on-going in France. A reliable estimate of seismic margins is possible only if all uncertainties, epistemic and aleatory, are effectively identified, quantified and integrated in the seismic risk analysis. SINAPS@ brings together a multidisciplinary community of researchers and engineers from the academic and the nuclear world. SINAPS@ aims at exploring the uncertainties associated to databases, physical processes and methods used at each stage of seismic hazard, site effects, soil and structure interaction, structural and nuclear components vulnerability assessments, in a safety approach: the main objective is ultimately to identify the sources of potential seismic margins resulting from assumptions or when selecting the seismic design level or the design strategy. The whole project is built around an "integrating" work package enabling to test state-of-the-art practices and to challenge new methodologies for seismic risk assessment: the real case of KashiwazakiKariwa Japanese nuclear plant, shocked by the severe earthquake in 2007 provided a rich dataset which will be used to compare with the predictions. The present paper mostly illustrates the crucial links and interactions between all actors of the project to reach the objectives.
\end{abstract}




\section{INTRODUCTION}

\section{International and French contexts}

The SINAPS@ (Earthquake and Nuclear Plant - Ensuring and Sustaining Safety) research project is an ambitious contribution to the effort and challenges in earthquake engineering that national and international scientific community must reach. After the recent major natural events (2004 Indian Ocean magnitude (M) 9,1-9,3 earthquake (EQ) and tsunami; 2007 Chuetsu Oki Japan, M6,8 EQ and 2011 Tohoku M9 EQ and tsunami) that have caused historical human disasters, huge financial losses, industrial production and particularly nuclear ones are strongly challenged. Lessons learned from these events should allow increasing the level of safety of current and future nuclear facilities, especially through the improvement of risk assessment and associated mitigation methods.

Approaches for assessing the seismic hazard, seismic assumptions considered for the design of civil engineering structures and equipment are associated to practices, codes, standards and rules adopted at the national scale in countries with nuclear facilities. In France, the seismic risk is taken into account in the design and reassessment of nuclear plants (RFS 2001-01 (2001) and ASN Guide (2006), whereas international references exist such as the recommendations published by the IAEA. However, the March 2011 Tohoku Japanese earthquake followed by the mega-tsunami caused the major nuclear accident at Fukushima Daiichi NPP and puts question on seismic risk practices for nuclear plant safety. The complementary safety studies conducted in France (CSS) in the aftermath of the disaster highlight the need for operators to implement "a hard core" of material and organizational measures to control the fundamental safety functions in extreme situations," and in general, for their nuclear plant, "to increase as soon as possible, beyond safety margins they already have, their robustness to extreme situations" (see report ECS ASN (2012)).

SINAPS@ aims to explore the uncertainties associated to data, knowledge of the physical processes and methods that are used at each stage of the seismic hazard and seismic vulnerability of structures and components assessment, as part of a nuclear safety approach: the main goal is ultimately to identify the sources of potential seismic margins resulting from assumptions or when choosing the seismic design level (i.e. taking into account uncertainties by conservative choices) or the design strategy (conservative assumptions, choice of materials ...).

\section{SINAPS@: a French partnership to progress on some "French specificities"}

SINAPS@ aims to bring scientific demonstrations and to make recommendations to improve the seismic risk management and then safety of current and future French facilities: the strength of the project is to bring together the expertise of:

- geologists, geophysicists, seismologists and statisticians to study the various components of the seismic hazard,

- material modelling, soil mechanics and geotechnical specialists, civil engineers, to characterize the response of soil and structures to seismic loading,

- researchers from both academic, industrial and the nuclear world,

- scientists recognized as experts and heavily involved in regulatory body transcription of best practice in seismic risk management (some strongly involved in the CSS), see Figure 1. 


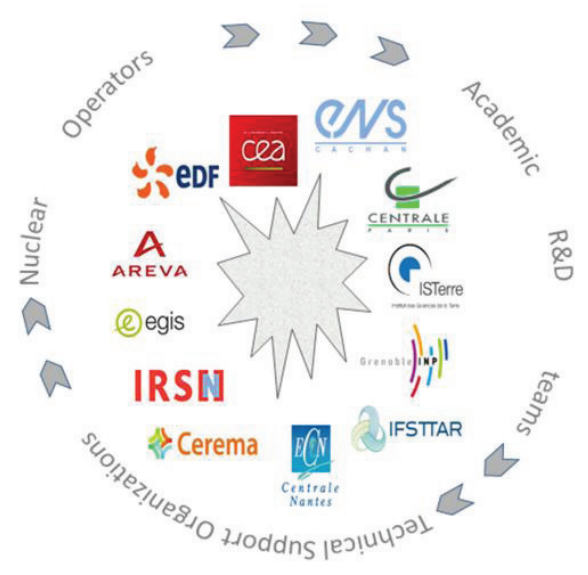

Figure 1.SINAPS@ partnership.

\section{SINAPS@RESEARCH PROJECT PRESENTATION}

\section{SINAPS@scientific organization}

SINAPS@ is structured around five "work packages (WP)" that strongly interact (i) WP 1, "Seismic Hazard", (ii) WP 2, "Non Linear Site Effects and Interactions between the seismic vibratory field, the soil and structures", (iii) WP 3, " Behavior of structures and equipment to seismic loading, seismic isolation and reinforcement processes ", and (iv) WP 4, devoted to the "Seismic Risk Assessment" and aiming at integrating the first 3 WP's findings. These four WP's are mainly based on empirical and numerical approaches. The WP 5 is based on the experimental laboratory approach, addressing issues for which the databases poverty and/or lack of feedback and/or whose resolution by conventional simulation approaches remains too uncertain. This WP 5 is based on the seismic experimental platform Tamaris CEA-Saclay including the most powerful Azalée shaking table (http://www-tamaris.cea.fr/) in Europe. Within the SINAPS@ project, tests involving interaction between buildings are planned. The test results combined with simulations should allow providing important comments and/or recommendations regarding the topic of building to building interaction.

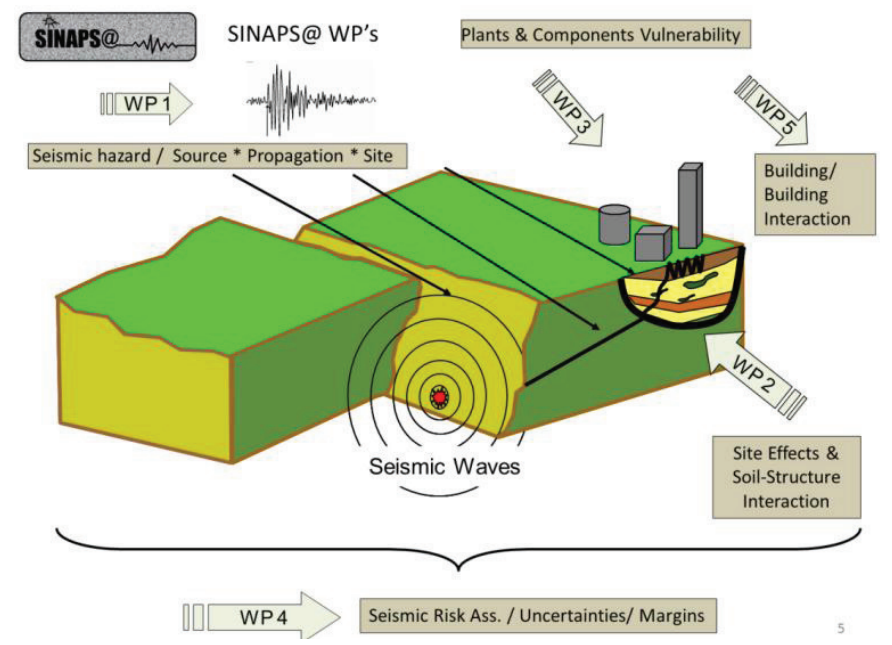

Figure 2.SINAPS@ Scientific Work Packages Interactions 
Finally, the dissemination of knowledge coming from SINAPS@ WP 1-5 research is done through a training WP promoting state of the art methods to assess the seismic risk for the safety of nuclear plants: one session for students in 2016 and a second one in 2017 under the International Seismic Safety Centre IAEA umbrella for researchers and people from earthquake engineering community.

Identifying the nuclear plant seismic margins requests a permanent dialogue between the three main domains of seismic risk assessment i.e. (hazard, vulnerability and issues). SINAPS@ governance project has established a monitoring committee, composed of national and international experts in research and seismic engineering fields, which would assess, throughout the project duration, effective communication between people in all work packages and consistency of research activities. The SINAPS@ project addresses the issue of nuclear facilities (structures and components) safety only with respect to the seismic action. This does not prejudge the dominant role of the seismic action regarding other loads (wind, snow, flood, static constraints etc.).

\section{SINAPS@'s KEY SCIENTIFIC ISSUES}

SINAPS@ is a 5 years project which began on September 2014. In the following section we present the philosophy and most important scientific issues addressed by SINAPS@ illustrating some preliminary results. In this paper we choose to focus on WP4 which has an "integrator role" of knowledge and improvements from WP1, 2 and 3. WP3, WP5 and WP6 will not be addressed, as they will produce results later in the project.

\section{SINAPS@project main issue: towards Potential Sources of Seismic Margins Identification}

Risk assessment involves the aggregation of individual elements of the analysis chain in the convolution of the seismic hazard and the various partial conditional probabilistic estimates of the damage, including the vulnerabilities of structures and equipment, as defined in using the widespread concept of fragility curves (Figure 3). It can be established during the design process as during a periodic safety review of the plant or component: this safety plant review phase is clearly the purpose of this project. It can also be practiced in a systematic framework in a probabilistic safety analysis, having defined by a preliminary analysis a fault tree system and associated criteria, based on a multi-physics analysis. The approaches advocated in the committees of European experts aim at building integrated methods of deterministic / probabilistic modeling (IDPSA) (see Zio 2014) for the safety of light water reactors, treating random and epistemic uncertainties see USNRC (1991) interactions between equipment important for safety and unclassified material, operator actions ... and mobilising the computing resources available today.

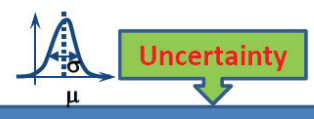

\section{analysis chain : from the fault to probabilistic floor spectra}

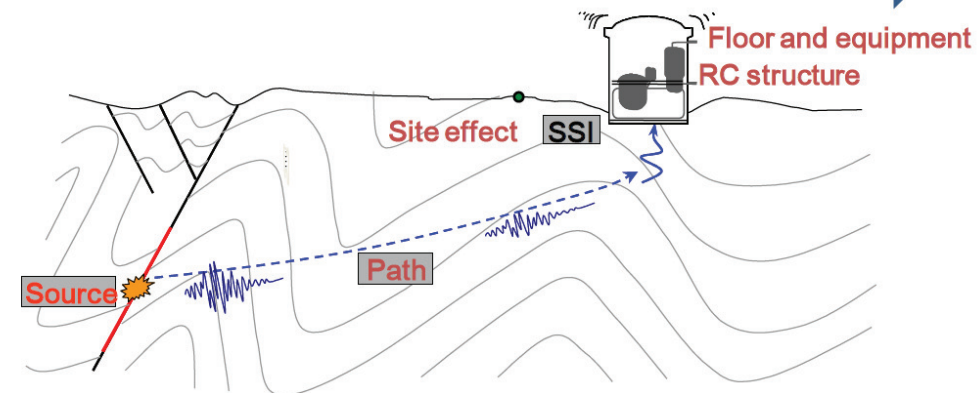

Figure 3. A continuous approach for probabilistic risk analysis from the seismic source, through site effects, soil-structure interaction up to sensitive components, integrating uncertainties. 
The general purpose is to establish the means to identify margins coming from the design in seismic analysis methods used during the reassessment stage of the plant cf. IAEA (2002) first in the methods of calculation stricto sensu and through the data considered for modeling, but also by taking into account the ductility capacity of soil, materials and structures. Indeed, the sequence of steps in the seismic analysis that integrate several conservatisms (in the method and in the data) results in a total seismic margin that would overestimate the "realistic" seismic response. This issue is addressed in the WP 4 of SINAPS@ project focusing on the demonstrative study KARISMA, (already considered for the benchmark organized by the IAEA in 2010, see reference IAEA 2013) based on the event experience feedback July 16, 2007 earthquake occurred at the Kashiwazaki-Kariwa NPP (TEPCO), for which a rich set of data throughout the analysis chain is available.

The purpose of the WP4 demonstrative study is to implement and evaluate the methodology leveraging various contributions of SINAPS@ project at each step of the seismic analysis on a concrete case of nuclear plant, identifying phenomena contributing to a "best-estimate" response (see Voldoire (2006)). The KARISMA case concerns an event of a higher level than those usually considered in France, but is quite comparable to some "maximal hypothesis" coming from rare paleo earthquake indices and fully coherent in the post-Fukushima context where extreme hazards have to be studied. It is then expected from this study demonstrative evidences (challenged against real seismic data) to establish new methods of justification that will be implemented in the future in the French context, taking advantages of the most relevant and recent research. This is fully in line with the objective to identify acceptable justification methods of structures and equipment against required performance requirements, as indicated by the ASN/IRS /EDF group (2012) which formulated in 2012 shared recommendations on the mode of application of the justification methods in ASN/2/01 Guide (2006).

Works and sensitivity studies performed in WP4, and particularly on the basis of the demonstrative study, should enable SINAPS@ partners to comment and prioritize sources of potential margins, requiring nevertheless defining clearly the reference damage criteria.

\section{Presentation of the Risk Assessment WP4 and its pivotal role in SINAPS@whole project}

As introduced above WP4 has the following two objectives:

(i) set up the overall methodological approach using the various products of the project and by comparing their implementation in a coordinated global validation work; a demonstrative case study, based on actual data will be conducted, preparing technology transfer to engineering. It is proposed to deal with the case of the KARISMA benchmark which has been controlled by the IAEA, the NEA and the OECD between 2010 and 2012, in cooperation with TEPCO. This benchmark has the advantage of corresponding to an real case of nuclear plant (unit 7 of Kashiwazaki-Kariwa site) having undergone a strong earthquake beyond design criteria, for which there is a rich set of data (measures, methods of analysis) on both the loading, the effect of site, Soil-Structure interaction and behaviour of civil work structures [IAEATECDOC-1722 (2013)]. The exceedance of 2007 NCOE ground motions recorded on the KK NPP with respect to the design levels (Figure 4) initiated in the international community the need to better characterize and quantify seismic margins of existing NPP. 

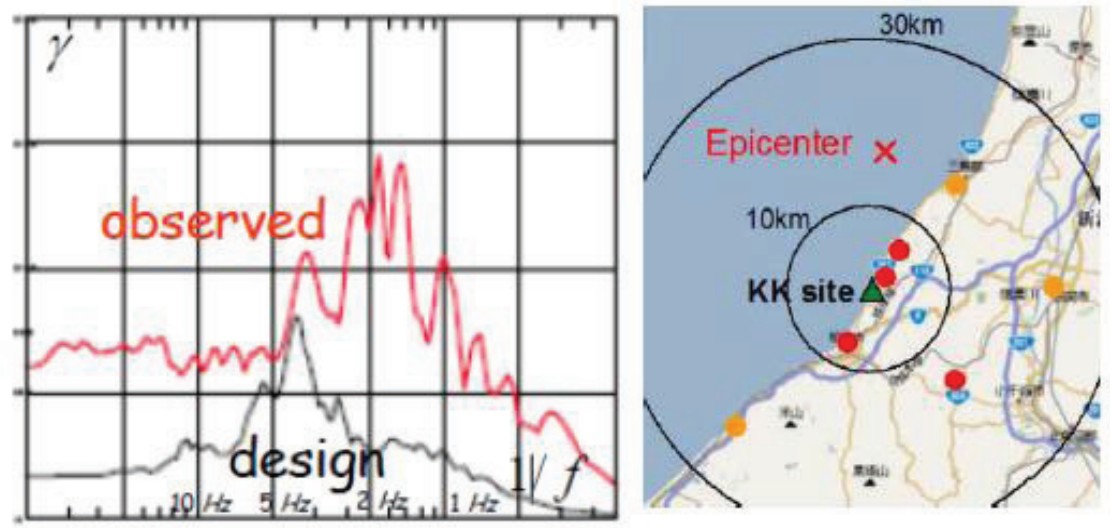

Figure 4. Chuetsu Oki 2007 EQ and KK NPP Location (right). Illustration of recorded strong motion on site exceeding the seismic design level (left).

The implementation on the KARISMA case-study will consist in nonlinear transient simulations of nuclear building behaviour, taking into account the site effects, the interaction between Soil, Structure and large equipment. Finally fragility curves and "HCLPF" [high confidence low probability of failure] by numerical methods of propagation of uncertainties will be produced. This task is managed in 2 phases during the project (1) the initial stage where basic knowledge available at the beginning of SINAPS@ and current best-estimate practices will be used, (2) the final stage, where the major achievements of the project SINAPS@ will be considered. Figure 5 illustrates geological data and structural Reactor Building model that will be used as input in the initial phase. The identification of the sources (hypothesis, data, methods, uncertainties) that impact the amount of seismic margins (or provisions) should be appreciated considering results coming the initial and final stages.

(ii) to consolidate methods of probabilistic risk assessment, including algorithmic performance aspect for practical studies, even if R\&D activities in the disciplinary field of stochastic analysis and removal of associated technological barriers have to be conducted in other collaborative projects (indeed, the necessary methods are beyond the scope of the seismic hazard and concern other natural phenomena such as storms, waves...).
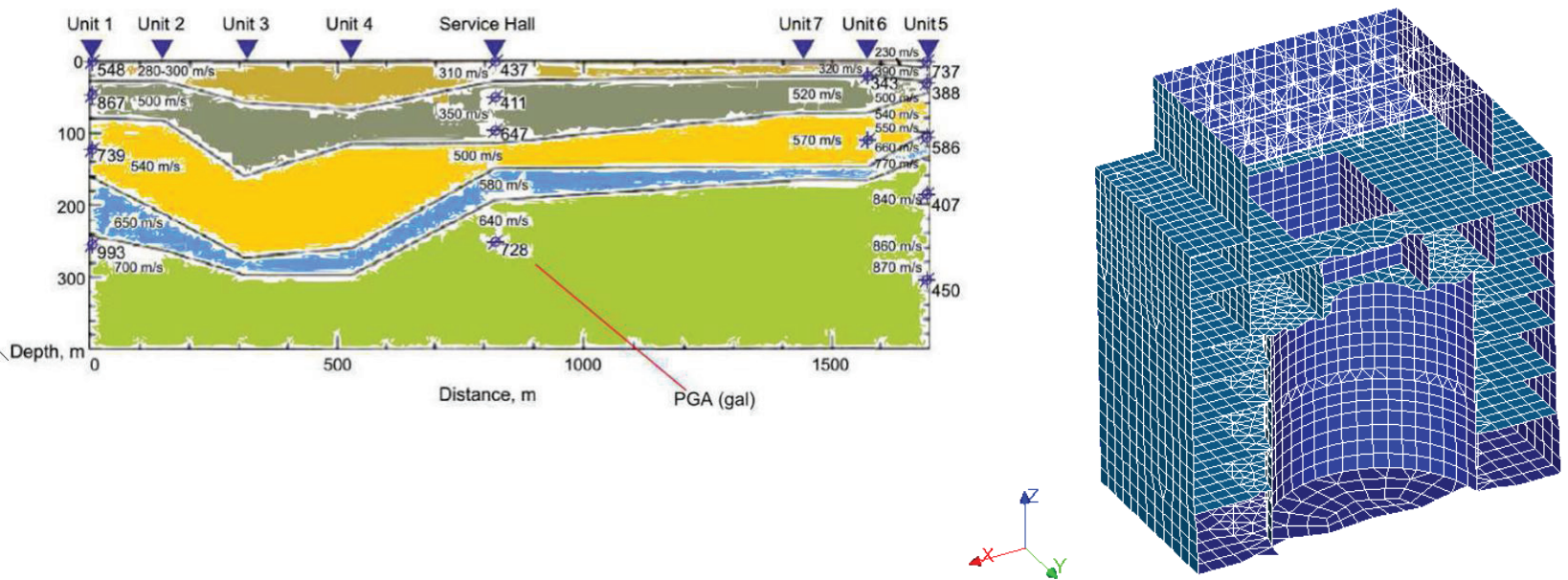

Figure 5. (Left) General 2D stratigraphy of the KK site (from O. V. Pavlenko and K. Irikura), (Right) Example of structural model of Reactor Building Unit 7, as used during the $2010 \mathrm{KK}$ benchmark, used in the intial phase of KARISMA test case in SINAPS@ WP4. From [Banci and Zentner 2015]. 
The WP4 has a pivotal role in SINAPS@ due to a need of:

- expertise on the seismic loading hypothesis coming from seismologists of WP1;

- a numerical tool to compute non-linear soil and structure interaction, specific analysis on nonlinear site-effects, and finally coupling SSI and site effects with structural seismic behavior numerical simulation: these tasks require a strong interaction with WP2,

- nonlinear reinforced concrete structural predicting models, adapted for the WP4 purposes, provided by WP3, and expertise on methods used to predict the seismic motion transferred from structure up to equipment.

\section{The Seismic Hazard Assessment WP1: a key expertise in SINAPS@ regarding the relevance of seismic loadings used in the whole seismic risk assessment chain}

WP1 is focused on the seismic hazard assessment (S.H.A.) on the French metropolitan territory, characterized by a spatially heterogeneous and low rate of seismicity. A key scientific issue addressed in the WP1 is to analyse if the methods used for assessing the seismic hazard are suitable in terms of knowledge or lack of knowledge about the seismicity and associated physical processes. Historically, the deterministic approaches have been supported and developed in the regulatory standards and especially in countries with a low seismicity, and this especially for the nuclear power plant safety (RFS 2001-01 in France). International references and practice (IAEA , 2002) standards and guides, the implementation of Eurocode 8 are an incentive for the development of the probabilistic approaches, even in countries with a deterministic tradition such as the France. This tendency has been confirmed after the Fukushima accident, leading us to question the assumptions and the methods adopted for the hazard assessment at this site and the requirements of the Japanese regulatory standards. Complementary safety studies (ECS) performed in France have been reviewed by European experts and they recommended a completion of the classical deterministic method by a probabilistic seismic hazard assessment. Furthermore, the probabilistic capacity to integrate the random and epistemic uncertainties makes it powerful and popular. However, the levels of hazard are stronger and are associated with large confidence intervals. The use of PSHA results then address specific questions and new expert discussions are thus raised (recent feedbacks from the Swiss PEGASOS project and the Thyspunt NPP PSHA study - see Bommer et al., 2014). Beyond methodological debates the true issues of SINAPS@'s WP1are (i) to systematically identify, quantify all uncertainties and clarify their treatment in the S.H.A, and (ii) to provide to WP2, 3 and 4 researchers and engineers reliable and adapted seismic inputs in coherence with the methodologies used to predict site effects, SSI and risk: for this latter aspect a dedicated SINAPS@PhD thesis just began.

The WP1 objectives are:

(1) to characterize the typical French data by the most appropriate and validated methods to generate metadata and their uncertainties,

(2) to suggest a ranking of the key parameters in the seismic hazard assessment methodology and estimate the associated uncertainties to guide future research,

(3) to assess the sensitivity of deterministic approaches such as the RFS 2001-01 and probabilistic approaches according to the known input data,

(4) make recommendations for the advancement of the French regulatory standards,

(5) to provide a relevant description of the seismic hazard for the engineering needs.

In the current studies conducted by WP1, one should mention Laurendeau et al. ongoing (2015) works which results should have a strong impact on seismic hazard assessment, whatever the retained approach (deterministic or probabilistic). The final goal of Laurendeau et al. (2015) is to compare various methods to assess ground motions for hard rock condition (site effects being fully estimated by WP2), and if possible to propose a specific Ground Motion Prediction Equation (GMPE). Currently, huge uncertainties in the S.H.A. comes from the use of classical GMPE's through 2 sources: (i) first one is 
related to the ergodic assumption used to derive the GMPEs and (ii) second comes from the geological/rheology of the site defined through the $\mathrm{Vs}_{30 \mathrm{~m}}$ proxy usually very poorly constrained. Recent works, (as the PSHA performed for the Thyspunt NPP, Bommer et al. (2014), see Figure 6) propose to apply to the original GMPE's several correcting coefficients in order to be "site specific" consistent: these corrections are known as the "single station sigma" (correcting the ergodic assumption), and the "Host to Target" correction introducing a new proxy Kappa0. Laurendeau et al. (2015) consider that such approach remain difficult to apply, especially due to the lack of real strong motions recorded at well characterized seismic stations, and most of the GMPEs being derived from surface strong motions which are "polluted" by superficial soil alteration even for "rock condition". The strategy proposed by Laurendeau et al. (2015) to avoid these biases is: (1) in a first way, to use strong motion recorded at depth on very hard rock condition and to correct them of the depth effects; (2) in a second way, to use strong motion recorded at surface on soft-soil to rock condition and to correct them of the near surface materials response. In the frame of SINAPS@ the computation of realistic site effect (i.e. geometry 1D, 2D, 3D, linear or non-linear behaviour) will be assessed by WP2 considering the input motion provided by WP1 at "reference hard rock in depth".

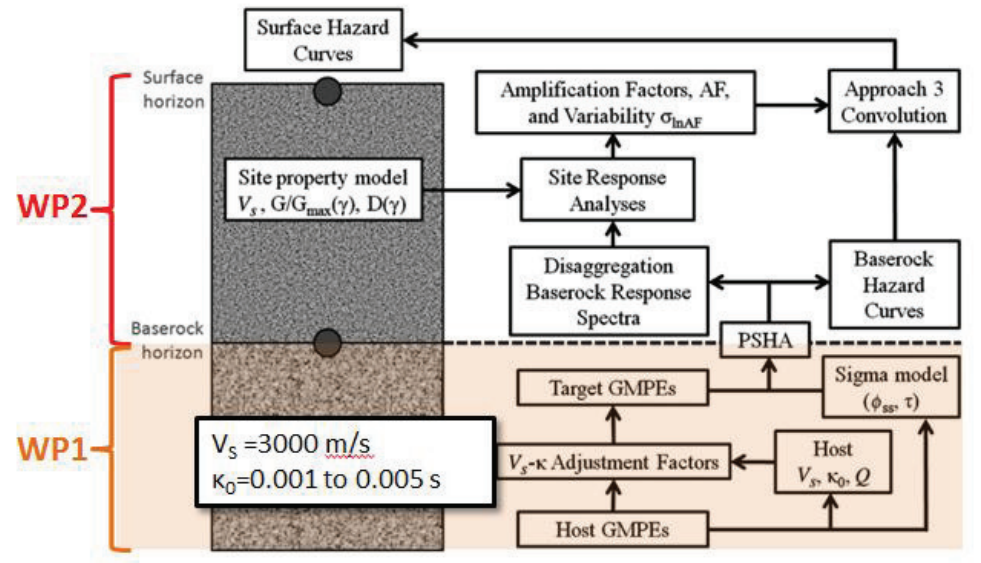

Figure 6. After Rodriguez et al. (BSSA, 2014). Approach used in a site-specific PSHA for the Thyspunt Nuclear Siting Project (Bommer et al., 2014).

Among the current practices at least in France that will be challenged in SINAPS@'s WP1, one of them is the way in which the seismic source and its potential are defined to assess the hazard. Currently, in the frame of the RFS2001-01 approach the seismic source and associated ground motions are evaluated considering that the seismic energy is concentrated on a unique point ("point source approximation"). The reality is different, a seismic source, whatever the considered magnitude consists in a geometrically extended fault, usually complex and segmented. Ignoring this complexity leads to simplify the reality, and from the S.H.A. point of view may conduct either to under or over predict the expected strong motion, depending on the location and the site with respect to the source: some near source effects, such as directivity (focusing of seismic waves in the direction of the rupture propagation) are then ignored while many earthquakes have experienced these effects associated to a huge variability of recorded strong motions some of them being clearly damaging ("killer pulse") due to a specific frequency content and large amplitude. A first study performed in WP1 by T. Chartier et al. (2014) using a probabilistic approach investigated the influence of faulting models and zoning, and analyzed the impact on the hazard results on associated hypothesis, that are (i) the geometry of the faults (ii) their seismic potential (i.e. slip rate), as shown Figure 7. From this study focused in the Upper Rhine Grabben Eastern France, a strong variability in the PSHA results appears mainly induced by the uncertainty on slip rate associated to the faults. This latter parameter (which is not directly used in the current deterministic S.H.A. French practice) is very poorly constrained in France, and should be improved through paleo seismological 
studies and long term geodetic measurements. In this application the choice of the GMPE appears also crucial finally controlling the hazard level (Figure 8).

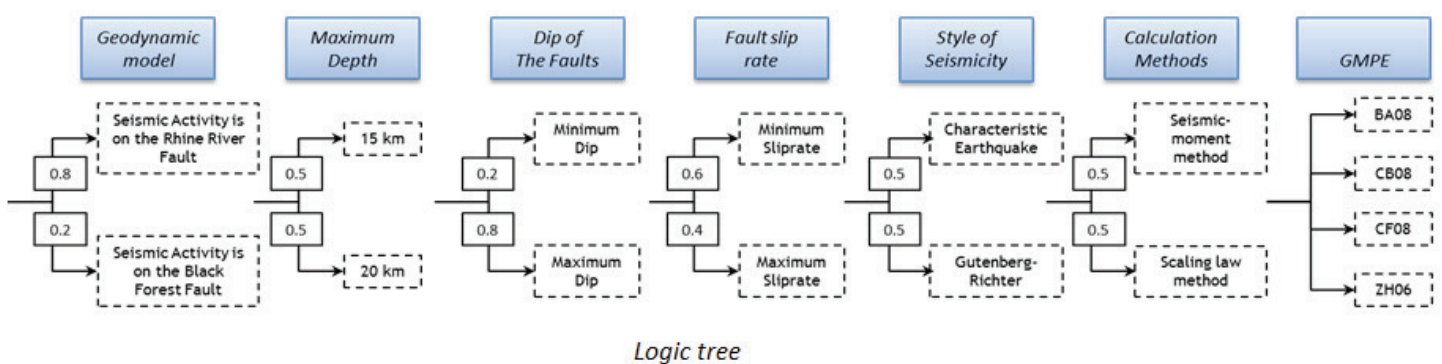

Figure 7. Exploration epistemic uncertainty through a logic tree in T. Chartier et al. 2014 study.

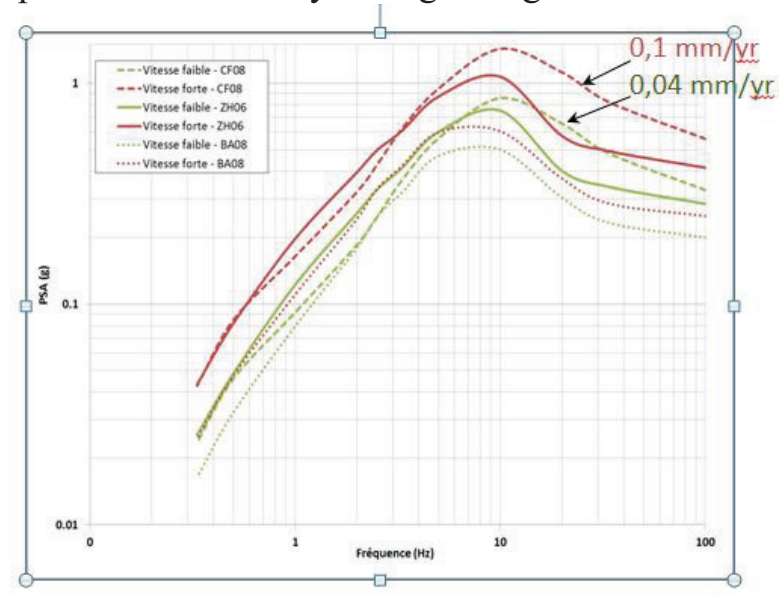

Figure 8. Sensitivity in the PSHA UHS results : influence of the slip rate value (red curves high value, green curves low value), and considering 3 GMPEs, from T. Chartier et al., 2014.

\section{Non-linear interaction between both near and far seismic fields, the soil and structures: scope of WP2}

In the framework of the wave propagation from the source to the equipment at the structure, the WP2 is placed at the interface between the soil and the structure, the seismology and the structure dynamics, the hazard and the structure vulnerability. Even if the soil-structure effects are well known from 70's they have often been considered in the conception under simplified assumptions: Winkler springs, uniform incident field, shallow foundations or rigid linear equivalent soil behaviour ...

Many of these assumptions have been improved in recent years, which allow highlighting safety margins (Mylonakis and Gazetas 2008). These works also showed the sensitivity to high uncertainty attached both to seismic loading and on the soil properties surrounding the structure. Moreover, so as to take into account extreme events in the post-elastic behaviour of structures, it is necessary to have a more detailed description of the seismic loading, in both time and space, exceeding the given maximum acceleration or code spectrum. Finally, the instrumental and theoretical seismology has highlighted the complexity and variability of a field of seismic waves: near field effect, site effects, non-linear filtering strong movements, spatial variability (Luco and de Barros 2004). These advances build now a big picture, which combines various methods with difficulties to be associated and sometimes inconsistent with the regulations and common methods used in the world (Pitilakis 2010, Cottereau 2007 and 2008).

The main objectives of the WP 2 are to:

(1) Propose a global methodology based on both existing methods and tools : i) using large earthquake data bases, ii) using non-linear analyses for both the soil and structure, iii) defining 
the validity of simplified approaches, iv) accounting for the variability of motions and quantifying their uncertainties.

(2) Develop an advanced and unified computational tool to study the propagation from the source to the structure, and capable to reduce the uncertainties.

(3) Compare these methods to the recent data so as to highlight the main sources of uncertainties; random and epistemic ones and finally propose experimental campaigns to reduce the epistemic component.

Without enter into details of the numerous research activities performed in this WP, we briefly highlight 2 topics currently ongoing: (i) the choice of "a validation site" and (ii) the development of an integrated simulation tool accounting for uncertainties for the source-to-structure seismic wave propagation.

(i) On the 26th January 2014, a Mw=6.2 earthquake shook the island of Kefalonia (Figure 9 Left). It was decided to launch a "SINAPS@ post-seismic survey" with two main objectives: 1/ install temporary accelerometers in anticipation to the installation of the definitive permanent array in order to record possible strong after-shocks, 2/ install a dense sensors array in order to get a database to study spatial short-scale variably. This kind of database, even if it does not address the non-linearity issue, is also essential for soil-structure interaction research done within the Sinaps@'s WP2, to characterize the spatial variability and coherency of seismic motion. The temporary accelerometric network is in operation since February $3^{\text {rd }}, 2014$ (few hours after the second strong earthquake with $\mathrm{Mw}=6.0$ ) and recorded several thousands of events. A first analysis of this database allowed computing standard spectral ratios between a rock site and several sites within the basin that allow confirming the location of the future vertical array. The dense array was composed by 21 broadband seismometers, arranged on a five branches star with a maximum radius $180 \mathrm{~m}$. It was in operation over a 5 weeks period. A database composed by more than 1800 well-recorded earthquakes has been built. These two outstanding databases are already and will be extensively used within the whole Sinaps@ program. Figure 9 (Right) illustrates linear site effects due to rheology and geometry recorded by the SINAPS@ accelerometric network.
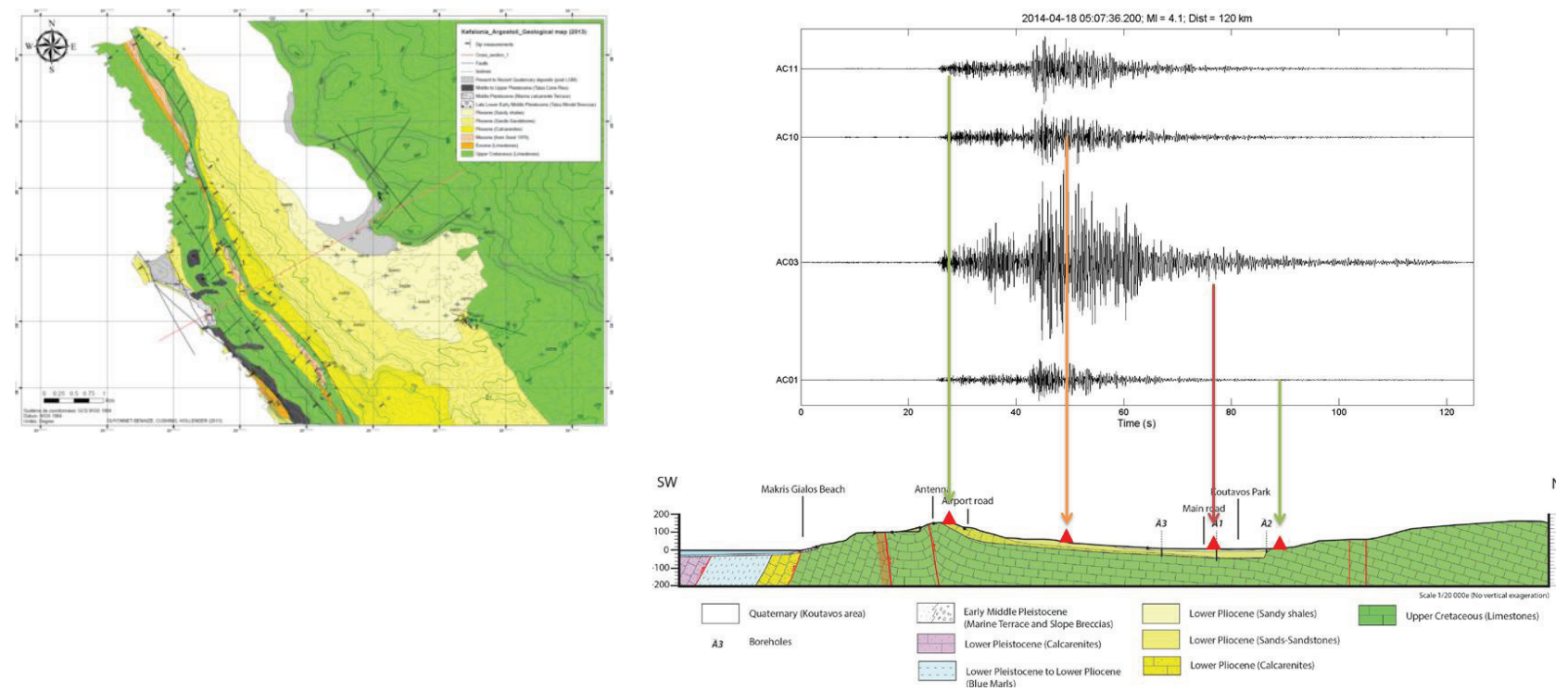

Figure 9. (Left) New geological map of the Argostoli area, Kefalonia (Cushing and Guyonnet-Benaize 2013), (Right) Recorded weak motions across the Argostoli basin (magnitude 4,1 event located at 120km, exhibiting site effects, from Hollender and al. 2014.

(ii) The development of a non-linear and probabilistic model at a large scale, from the source to the 
structure is a main objective of WP2 whose issues are to implement properly a probabilistic approach for risk analyses and scenarios (including seismic source and random soil properties), defining an adequate non-linear model of the soil allowing an accurate site effects evaluation, and finally to couple with with structural simulation tools for vulnerability analyses. The choice of the WP2 is to develop this tool using the spectral element method in 3D (SEM3D), and the work is ongoing (Figure 10).

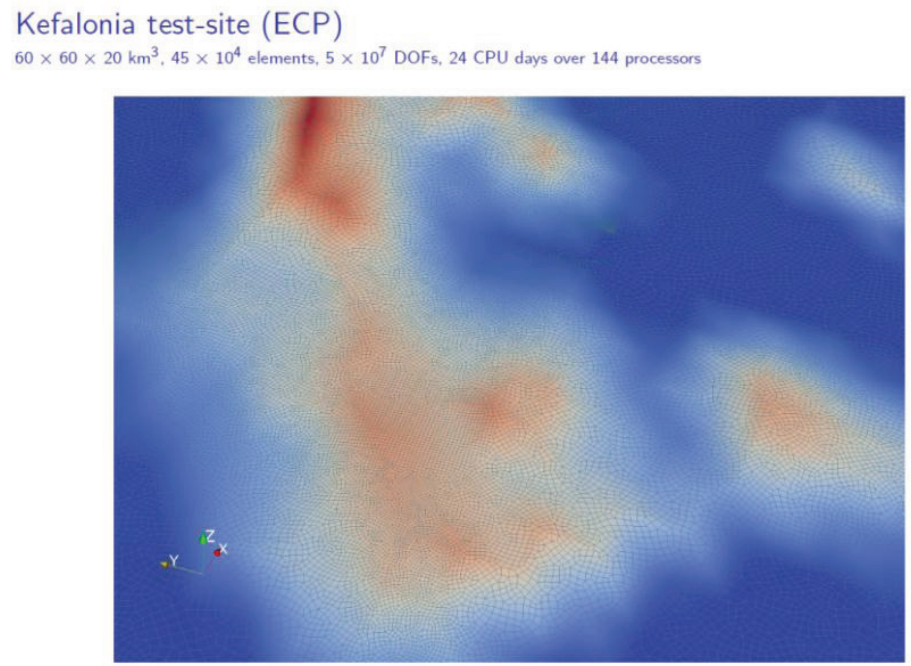

Figure10. Preliminary simulation using the SEM3D tool relevant to the Kefalonia SINAPS@ test-case (Cottereau et al., 2014).

\section{CONCLUSION}

SINAPS@ shall focus on a continuous analysis of completeness and gaps in data bases (all data types, from geology, seismology, site characterization and materials), of the reliability or deficiency of models available to describe physical phenomena (prediction of seismic motion, site effects, SSI, materials constitutive laws in non-linear domain), and of the relevance or weakness of methodologies used to performed seismic risk assessment. This critical analysis conducted confronting methods and available data to the international state of the art will systematically address the uncertainties issue. This work is essential to provide background information on regulatory approaches currently applied in France to account for seismic risk in nuclear safety context (RFS2001-01 [1] to estimate site specific seismic hazard level, and the / ASN /2/01 GUIDE specifying the provisions of seismic design of civil works and equipment, and acceptable methods for estimating the seismic response of structures interacting with the equipment. Then proposals or recommendations will be made about the potential applicability of new approaches accounting more realistically for the real behaviours of soil, structures and materials under high seismic loadings, with explicit integration of uncertainties. SINAPS@ challenges to provide the best data, improve, validate and disseminate new methodologies for seismic risk assessment, quantifying their reliability, and finally enabling authorities to take consolidated decisions from an economical and societal point of view. Then SINAPS@ should allow all the actors to better justify the level of safety of the facilities and to define the appropriate arrangements to this safety level maintain over time, in the French context, exploiting the most recent research. 


\section{ACKNOWLEDGMENT}

The work carried out under the SINAPS@ project receives French funding managed by the National Research Agency under the program "Future Investments" (SINAPS@, reference No. ANR-11-RSNR0022). SINAPS@ is a SEISM Institute project (http://www.institut-seism.fr/en/).

\section{REFERENCES}

"RFS2001-01, Règle fondamentale de sûreté n²001-01 relatives aux installations nucléaires de base. Détermination du risque sismique pour la sûreté des installations nucléaires de base", (2001), Nuclear Authority Safety website (http://www.asn.fr/index.php/Divers/Autres-RFS/RFS-2001-01).

"Guide/ASN/2/01, Prise en compte du risque sismique à la conception des ouvrages de génie civil des installations nucléaires de base, à l'exception des stockages à long terme des déchets, radioactifs", (2006), Nuclear Authority Safety website (http://www.asn.fr/index.php/Divers/Autres-RFS/Guide-ASN-Guide-2-01-exRFS-V.2.g).

ECS, "Evaluations Complémentaires de Sûreté, rapport de l'Autorité de Sûreté ", (December 2011), Nuclear Authority Safety website (http://www.asn.fr/index.php/L-ASN-en-region/Division-deMarseille/Actualites-de-votre-region/Rapport-de-l-ASN-sur-les-evaluations-complementaires-de-surete-ECS).

Zio Enrico, Integrated deterministic and probabilistic safety analysis: concepts, challenges, research directions, (2014) Nuclear Engineering and Design, , pp.1-7.

International Atomic Energy Agency (IAEA), 2002. Evaluation of Seismic Hazards for Nuclear Power Plants, Safety Guide N NS-G3.3.

IAEA-Tecdoc, Review of Seismic Evaluation Methodologies for Nuclear Power Plants Based on a Benchmark Exercise. International Atomic Energy Agency, (2013). Altinyollar A. et al., VIENNA, IAEA-TECDOC-1722.

USNRC, Procedural and Submittal Guidance for the Individual Plant Examination of External Events (IPEEE) for Severe Accident Vulnerabilities, (June 1991), US-NRC. NUREG-1407.

Voldoire F., Computational methods applied to the seismic margin assessment of power plants and equipment, (September 2006), Paper Number: 1038. First European Conference on Earthquake Engineering and Seismology, Geneva, Switzerland.

Laurendeau A., Foundotos, L., Hollender F., Ktenidou, O-J. and Hernandez, B. (2015). Towards the Definition of Reference Motions $(1000<\mathrm{VS}<3000 \mathrm{~m} / \mathrm{s})$ : Estimating Transfer Functions to Correct KiK-net 'Rock' Sites $(500<\mathrm{VS} 30<1500 \mathrm{~m} / \mathrm{s})$ for Site Effects. Seismological Research Letters 86 (2B), pp. 661-662. doi: 10.1785/0220150017.

Rodriguez-Marek, A., Rathje, E. M., Bommer, J. J., Scherbaum, F., \& Stafford, P. J. (2014). Application of Single-Station Sigma and Site-Response Characterization in a Probabilistic Seismic-Hazard Analysis for a New Nuclear Site. Bulletin of the Seismological Society of America, 104: 1601-1619. 
Bommer, J.J., K.J. Coppersmith, R.T. Coppersmith, K.L. Hanson, A. Mangongolo, J. Neveling, E.M. Rathje, A. Rodriguez-Marek, F. Scherbaum, R. Shelembe, P.J. Stafford \& F.O. Strasser (2014). A SSHAC Level 3 probabilistic seismic hazard analysis for a new-build nuclear site in South Africa. Earthquake Spectra, doi: http://dx.doi.org/10.1193/060913EQS145M.

Chartier Thomas, Christophe Clément and Hervé Jomard, "Etude probabiliste de l'aléa sismique pour un site du Fossé Rhénan Supérieur” (2014), Rapport IRSN/PRP-DGE-2014-00027, SINAPS@-WP1.

Mylonakis G. and Gazetas G., Seismic soil-structure interaction: beneficial or detrimental, (2008) $J$. Earthquake Engineering, 4:3, 277-301.

Luco, J.E., F. C. de Barros, Assessment of predictions of the response of the Hualien containment model during forced vibration tests, (2004) Soil Dyn. Earth. Engng. 24, 1013-1035, 2004.

D. Pitilakis and D. Clouteau, Equivalent linear substructure approximation of soil-foundation-structure interaction: model presentation and validation, (2010), Bull. Earth. Engng. 8, 257-282.

Cottereau R, Clouteau D, Soize C. Construction of a probabilistic model for impedance matrices, (2007), Computer Methods in Applied Mechanics and Engineering; 196(17-20):2252-2268.

Cottereau R, Clouteau D, Soize C., Probabilistic impedance of foundation: Impact of the seismic design on uncertain soils, Earthquake Engineering \& Structural Dynamics, (2008), Vol. 37, Issue 6, pages 899918.

Hollender F., V. Perron, Sinaps@ Kefalonia test-site: results of the preliminary geophysical survey and presentation of database resulting from the post-seismic campaign, (2014) Abstract for the 2014 SINAPS@plenary session,20\&21 November 2014.

Cottereau et al. 2014, Common developments of an integrated simulation tool for the source-to-structure seismic wave propagation, (2014) Abstract for the 2014 SINAPS@ plenary session, 20 \& 21 November 2014. 